\title{
Linking life history traits to pollinator loss in fragmented calcareous grasslands
}

\author{
Birgit Jauker · Jochen Krauss • Frank Jauker • \\ Ingolf Steffan-Dewenter
}

Received: 11 August 2011/Accepted: 24 October 2012/Published online: 7 November 2012

(C) Springer Science+Business Media Dordrecht 2012

\begin{abstract}
To gain insight into the drivers of pollinator loss, a holistic approach to land-use change including habitat size, isolation, habitat quality and the surrounding landscape matrix is necessary. Moreover, species' responses to land-use change may differ depending on their life history traits such as dispersal ability, trophic level, or sociality. We assessed species richness and life history traits of wild bees in 32 calcareous grasslands in central Germany that differ in size, connectivity, resource availability and landscape context. Declining habitat area and, to a lesser degree, reduced diversity of the surrounding landscape were the key factors negatively influencing species richness. In the community-wide analysis, small body size
\end{abstract}

Electronic supplementary material The online version of this article (doi:10.1007/s10980-012-9820-6) contains supplementary material, which is available to authorized users.

B. Jauker $(\bowtie)$

Agroecology, Georg August University Göttingen,

Grisebachstr. 6, 37077 Göttingen, Germany

e-mail: birgit.jauker@bio.uni-giessen.de

Present Address:

B. Jauker · F. Jauker

Department of Animal Ecology, Justus Liebig University

Giessen, Heinrich-Buff-Ring 26-32, 35392 Giessen,

Germany

J. Krauss · I. Steffan-Dewenter

Department of Animal Ecology and Tropical Biology,

Biocenter, University of Würzburg, Am Hubland,

97074 Würzburg, Germany and solitary reproduction were traits that made species particularly vulnerable to habitat loss. Contrary to our expectations, cleptoparasitic species were not more affected by reduced habitat area and landscape diversity than nest-building species. We performed further detailed trait analyses within the family Halictidae to prevent possible confounding effects due to trait correlations across families. Here, social as opposed to solitary species were more affected by habitat loss. We conclude that the opposite pattern observed for all social bees was mainly caused by large-sized social bumblebee species with high mobility and large foraging distances. Our results demonstrate the risks of concealed trait interference when analyzing community-wide patterns of life history traits. As a consequence, conservation requirements of small social bee species might be overlooked by generalizations from community responses.

Keywords Biodiversity - Community ecology . Habitat fragmentation - Species-area relationships . Landscape diversity · Bees · Body size $\cdot$ Sociality · Trophic level

\section{Introduction}

Bees are the most important group of pollinators in many parts of the world (LaSalle and Gauld 1993) ensuring the pollination of wild plants (Burd 1994) and agricultural crops (Klein et al. 2007). While 
pollinator abundance is generally regarded a crucial factor for successful pollination in plant communities, pollinator diversity is of similar importance to plant reproduction (Blüthgen and Klein 2011). However, there is growing evidence for an ongoing decline of bee species richness in recent decades (Biesmeijer et al. 2006). As this decline is mirrored by an increasing dependency of world crops on pollination services, the conservation of pollinators will become increasingly important in the near future (Aizen et al. 2009).

One of the most detrimental factors affecting pollinator communities is the overall loss of suitable habitat and the resulting fragmentation into smaller and more isolated habitat patches (Fahrig 2003; Winfree et al. 2009). Populations in these small, isolated fragments suffer from increased extinction risks and decreased immigration rates compared to those in large, connected fragments (Hanski 1999; Kuussaari et al. 2009) resulting in reduced species richness in small, isolated fragments (Hendrickx et al. 2009; Brückmann et al. 2010). Main drivers of these species-area relationships are decreasing microhabitat diversity and lower resource availability (Rosenzweig 1995; Ricklefs and Lovette 1999).

Next to sufficient amounts of energy-rich nectar and protein-rich pollen, necessary resources for wild bees also include specific nest sites as well as materials for nest construction (Westrich 1996). In agricultural landscapes, bees can find these diverse resources e.g. in calcareous grasslands, a semi-natural grassland type that is one of the most species-rich habitats in central Europe (WallisDeVries et al. 2002; Krauss et al. 2010). However, during recent decades, calcareous grassland area has considerably declined (Poschlod and WallisDeVries 2002), severely threatening its diverse and unique flora and fauna (e.g. Krauss et al. 2003; Matthies et al. 2004; Krauss et al. 2010) and negatively affecting plant-pollinator communities (Rathcke and Jules 1993; Kearns et al. 1998).

Remaining calcareous grassland fragments are interspersed in an agricultural landscape matrix that shows a varying permeability for pollinators (Ricketts 2001). Whereas a homogeneous landscape-composed of only e.g. winter wheat fields-is likely to inhibit dispersal between metapopulations, a more diverse landscape providing pastures and other grasslands is more permeable for bees (Jauker et al. 2009). Many bee species are multi-habitat users. The entire home range of a bee often consists of several partial habitats, which only in combination provide the female bee with all necessary resources, i.e. nest sites, nest building material and food plants (Westrich 1996). Hence, a bee might use a calcareous grassland habitat for nesting, or foraging, or both and may further benefit from a complex matrix around the calcareous grasslands that contains other semi-natural habitats such as orchard meadows, hedgerows, and extensively managed grasslands. Even strongly anthropogenic landscape features such as parks, gardens and flowering crops offer various resources to support bee communities (Westphal et al. 2003; Winfree et al. 2007).

The scale, at which bees perceive the landscape is, however, species specific. Partial habitats have to match the foraging ranges, which are given by Gathmann and Tscharntke (2002) to be a few hundred meters for 16 examined solitary bee species and up to 3,000 $\mathrm{m}$ for bumblebees (Westphal et al. 2006). For many other bee species, foraging ranges are still unknown, but certain size measurements such as the distance between the bee's wing bases (inter-tegular distance, ITD) are good predictors of foraging ranges (Greenleaf et al. 2007).

Taking into account species specific ecological traits like the variation in flight capability is of critical importance in analyzing metapopulation dynamics (Moore et al. 2008). Species with poor dispersal abilities, species with specialized resource needs, as well as species at higher trophic levels are predicted to be more sensitive to habitat loss and reduced heterogeneity (Holt et al. 1999; Ewers and Didham 2006; Franzén et al. 2012). Hence, a better understanding of the effects of habitat loss on bee community changes can only be achieved when considering different life history traits of bee species (Cane et al. 2006). A recent study that takes life history traits into account indicates that diet breadth modifies responses of differently sized wild bees to habitat loss (Bommarco et al. 2010). However, possible tangled correlations between traits might constitute a problem in the analyses of entire bee communities, because traits of species are frequently not phylogenetically independent (Bielby et al. 2010). For example, when comparing responses of sociality to fragmentation, small species may be social or solitary, but effectively almost all large species are social bumblebees. To avoid the phylogenetic relatedness we separately analyze the closely 
related species group of the bee family Halictidae where the responses of social and solitary bee species with similar body size can be compared. Even though the members of the family Halictidae constitute a monophyletic taxon, they represent very different life history traits regarding social behavior and breeding strategy (Danforth et al. 2008). Social and solitary species occur as well as cleptoparasitic bees, thus allowing for a less phylogenetically biased analysis of trait-related responses to habitat fragmentation.

In this study, we examine the effects of fragmentation on bee species richness in semi-natural calcareous grasslands. We thereby take into account the availability and diversity of food resources within the grassland and the heterogeneity of other suitable habitats in the landscape matrix. In addition we consider the different life history traits of bees such as their size (inter-tegular distance-ITD) as an indicator for dispersal ability, cleptoparasitism as an indicator of higher trophic level, and their social status, i.e. whether their reproductive mode is solitary or in social colonies, as an indicator for e.g. resource utilization efficiency. We expect that small bees, cleptoparasitic bees, and solitary bees should be more sensitive to loss of semi-natural habitat than large, nest-building, and social bees. We analyze life history traits for all bee species and also within the monophyletic bee family Halicitidae separately.

\section{Materials and methods}

Study region, habitat and landscape characteristics

The study was conducted in the Leine-Weser Mountains around the city of Göttingen in Lower Saxony, Germany in 2004. The study region covers an area of about $2,000 \mathrm{~km}^{2}$ and is characterized by intensively managed agricultural areas and patchily distributed fragments of semi-natural habitats. Even though our study region includes a total of 285 calcareous grassland fragments, they cover only about $0.3 \%$ of the area. Calcareous grasslands occur on shallow, lime-rich soils, usually on south or south-west facing slopes and have sharp boundaries with surrounding habitats. They belong to the plant association Gentiano-Koelerietum and are extensively managed by sheep- or goat-herding, extensive mowing or annual removal of woody shrubs. We selected 32 calcareous grasslands that constituted the entire gradient of habitat area and connectivity in the study area. A map of the study region and study sites can be found in Krauss et al. (2003).

Quantification of calcareous grassland habitat area, connectivity and landscape diversity is based on Krauss et al. (2003). The area of the 32 grassland fragments was measured in 2000 with a differential GPS GEOmeter 12L (GEOsat GmbH, Wuppertal, Germany) and ranged from 314 to $51,395 \mathrm{~m}^{2}$.

Habitat connectivity ( $C$, inverse of isolation) measurements took into account all calcareous grasslands within a radius of $8 \mathrm{~km}$ around each study site $(j)$ and were calculated using Hanski's connectivity index (Hanski et al. 2000):

$C_{j}=\sum_{j \neq k} \exp \left(-a d_{j k}\right) A_{k}^{b}$

where $A$ is the area $\left(\mathrm{m}^{2}\right)$ and $d$ the distance $(\mathrm{km})$ from each neighboring grassland $(k)$. The parameter $a$ is a species-specific parameter describing the dispersal ability of a species and the parameter $b$ the scaling of immigration. Because specific $a$ values are not expected to affect the ranking of connectivity within a data set (Hanski 1999), it was set to $1 \mathrm{~km}$ as an assumed mean for the contributing bee species' emigration. Similarly, $b$ was set equal to one because no information is available on any possible influence of neighboring patch area for bee species' emigration. The connectivity values varied between 2,100 and 86,000 with large values signifying high connectivity. We also measured the distance of each study site to the nearest of the 285 calcareous grasslands, ranging from 55 to $1,894 \mathrm{~m}$.

Land cover of the entire study region was separated into eleven land-use types: arable land (42.15\%), forest $(36.80 \%)$, grassland (12.14 \%), built-up area (6.24 \%), other habitats $(1.48 \%)$, garden land $(0.31 \%)$, hedgerows $(0.30 \%)$, calcareous grasslands $(0.26 \%)$, orchard meadows $(0.20 \%)$, fen $(0.05 \%)$, and plantations $(0.06 \%)$ (ATKIS-DLM 25/1 Landesvermessung und Geobasisinformationen Niedersachsen 1991-1996, Hannover Germany; ATKIS-DLM 25/2 Hessisches Landesvermessungsamt 1996, Kassel, Germany). Using Geographic Information Systems (ArcView GIS 3.2, ESRI Geoinformatik, Hannover, Germany) the percentage land cover of the different habitat types was measured and used to calculate landscape diversity (Shannon index) at each of twelve different spatial scales ranging from 250 to $3,000 \mathrm{~m}$ radius around the 
center of the calcareous grasslands. Because landscape variables usually correlate across scales, we tested for the strength of the Pearson correlation between bee species richness and landscape diversity at each scale and used the scale that gave the highest correlation coefficient for further analysis.

\section{Pollinator sampling and resource availability}

Bee (Hymenoptera: Apoidea: Apiformes) surveys were conducted six times from April to September 2004 in each study site during sunny days with moderate wind speed. Easily distinguishable species like Apis mellifera, Bombus pascuorum etc. were identified on the wing, all other species were caught with a net and identified in the laboratory.

Bees were recorded during transect walks of a constant duration of five minutes. The length of each transect varied (mean transect length $=15.7 \pm 6.2 \mathrm{~m}$ $\mathrm{SD}$ ); transect width was always a 4 m-corridor. To achieve adequate sample sizes for the differently sized grassland fragments, we conducted four of the 5-mintransects (total $=20 \mathrm{~min}$ ) in eleven small sites $\left(314-1,133 \mathrm{~m}^{2}\right)$, eight 5 -min-transects $\quad($ total $=40$ min) in 13 medium fragments $\left(1,326-7,887 \mathrm{~m}^{2}\right)$, and twelve 5-min-transects (total $=60 \mathrm{~min}$ ) in eight large sites $\left(11,528-51,395 \mathrm{~m}^{2}\right)$. Data from the 5-min-transects of all six sampling events were pooled to obtain species richness per grassland fragment. See the statistical analyses section for different richness estimators applied in the analyses.

Resource availability of calcareous grasslands was quantified at each sampling event by determining plant species in flower and estimating their percent floral cover, monitoring the same transects as for sampling the bees. Flowering species within a 5-min-transect occurred at varied abundances, from 0.1 (1 flower per transect) to $40 \%$. The percent cover of all species was summed up for total flower cover of each transect. Values of all 5-min-transects were averaged to get flower cover per study site ranging from 5.0 to $20.5 \%$. Flower species richness was pooled over all transects and ranged from 24 to 56 flowering species per site.

\section{Assignment of life history traits}

Bee species were analyzed according to their life history traits such as dispersal ability, sociality and trophic level (see the species list in Online Resource 1 for assignments of traits). As a measure of dispersal ability we used the bees' body size, specifically the ITD, which is the distance between the two insertion points of the wings. The ITD serves as an indicator for the volume of the thoracic flight musculature (Cane 1987) and is strongly correlated with species mobility (Greenleaf et al. 2007). The ITD value for a given species is an average measure of up to four male and female individuals. In the analyses, the mean ITD of the sampled bee species in each study site is used as a continuous variable.

Bee species were separated into groups of solitary and social bees according to Westrich (1989). Social bees include species of the genera Bombus, Halictus and Lasioglossum that live in a colony characterized by cooperative brood care. A solitary bee cares only for her own offspring.

Further, we assigned the recorded bees to be either nest-building or cleptoparasitic. The latter, also called cuckoo bees, include the genera Melecta, Nomada, and Sphecodes and some Bombus spp. (those formerly placed in the genus $P$ sithyrus). They represent a higher trophic level because their larvae feed on the brood cell provisions of their bee hosts at the expense of the host larvae.

In order to avoid possible correlations of dispersal ability with other relevant traits, i.e. social behavior and trophic level, we performed focused analyses of social versus solitary nesting bees and nest-building versus cleptoparasitic species for the family Halictidae, i.e. species that are in the same league with respect to dispersal ability (mean ITD $=1.37 \pm 0.27 \mathrm{~mm}$ $\mathrm{SD})$. These species share the same phylogenetic history, reducing the potential bias that different trait combinations are generated by differences in relatedness. However, we are aware that whereas sociality has probably arisen and lost again a few times independently within the halictids (Danforth 2002), cleptoparasitism probably evolved only once in the halictid species of this study. Halictid cuckoo bees all belong to the single genus Sphecodes which constitutes a monophyletic group with a cleptoparasitic common ancestor (Danforth et al. 2008). Hence, the problem of phylogenetic non-independence may still remain for the comparison of cleptoparasites to nest-builders.

\section{Statistical analyses}

The statistical analyses were performed using the software R 2.9.1 for Windows (R Development Core 
Team 2006). Hierarchical partitioning (packages "hier.part" and "gtools", Mac Nally and Walsh 2004) was used to analyze the relative importance of the explanatory variables (flower cover, flower species richness, habitat area, landscape diversity, and habitat connectivity) on bee species richness (Chevan and Sutherland 1991; Olea et al. 2010). Hierarchical partitioning models show the relative importance of explanatory variables independent of their significances. For the most important variables we calculated simple regressions and noted the results in figure captions. Habitat area and connectivity were always $\log 10$-transformed and $\mathrm{x}$ in regression lines therefore stands for $\log 10(\mathrm{x})$ for these two explanatory variables. All model residuals met the assumptions of normality and homoscedasticity when visually inspected in normal probability and residuals vs. predicted values plots.

Habitat area was marginally correlated with landscape diversity at a $250 \mathrm{~m}$ radius $(r=0.32)$ and significantly correlated with resource availability, i.e. species richness $(r=0.54)$ and percent cover of flowering plants $(r=0.38$, see Online Resource 2 for correlations between explanatory variables). The two isolation indices, Hanski's connectivity index and distance to the nearest calcareous grassland, were correlated $(r=0.49)$. Since the distance measure also correlated with landscape diversity $(r=0.35)$, we used only the connectivity index for analyses.

With the occurrences of species per site and the average measure of ITD of each species present we tested if dispersal ability across species was influenced by flower cover, flower species richness, habitat area, landscape diversity, or connectivity using a hierarchical partitioning model. For the comparison of slopes of the two trophic level categories and the two sociality categories we used linear mixed effects models (package "nlme", Pinheiro et al. 2009) analyzing observed species richness of the bee groups. All possible combinations were calculated, explanatory variables entered each model in the following sequence: Trait-category, study site variable (either habitat area, connectivity, landscape diversity, flower cover, or flower species richness) and the interaction between trait-category and the study site variable. Significant interactions between species groups and patch characteristics indicate significant differences in slopes of the species groups' relationship to explanatory variables. The factor "Site" was included as a random factor. Because the semi-log regressions of species-area relationships with log-transformed area and untransformed species numbers account for absolute changes in species numbers, we additionally calculated $\log -\log$ regressions with $\log 10(n+1)$ for species richness to account for relative changes and present them in the electronic supplementary material.

To correct for the different sampling efforts in small, medium and large calcareous grassland fragments, we estimated the species number for an equal number of four 5-min-transects (i.e. $20 \mathrm{~min}$ total transect time) in each site using EstimateS version 8 (Colwell 2004). Because adults of particular bee species often occur for only a few weeks, we avoided effects of season-related species turnover by pooling species of the six sampling rounds conducted from April to September; i.e. we pooled the first 5-min-transects of all six samplings per site, then the second 5-min-transects, then the third etc. resulting in observed species richness. We used the pooled species richness per 5-min-transects to calculate species richness based on equal sample size as well as the second-order Jackknife richness estimator, an incidence based species richness estimator (Smith \& van Belle 1984) and one of the best established and most commonly used estimators (e.g. Palmer 1991). All statistical models were run with (1) both species richness estimators and (2) with the total species richness for the entire bee community. Species number estimation within functional groups was not possible due to the high numbers of sites with no or single species of a specific trait. However, we assume similar species detectability across functional groups due to the standard pollinator sampling protocol we used (Westphal et al. 2008). The relation of observed species in the entire community to overall estimated species richness was calculated to obtain a species saturation value per study site. Percent saturation varied between 52.1 and $80.0 \%$ (53.6-80.0\% for small, 52.1-76.9\% for intermediate, and 59.8-66.5\% for large sites). Although estimated richness was in some sites substantially higher than observed species richness, undersampling did not correlate significantly with habitat area (Spearman rank correlation, $\left.n=32, r_{S}=0.26, p=0.158\right)$ indicating that different sampling intensities did not affect speciesarea relationships.

Model residuals of each model were assessed for testing spatial autocorrelation using Moran's I correlograms with a lag distance of 2,241 m (mean distance between calcareous grasslands) and ten distance lags. 
Monte Carlo procedures with 5,000 permutations were used to detect significant departures of the observed data from the reference distribution. Despite some significant values at intermediate distance lags, there was no systematic pattern of spatial autocorrelation (Online Resource 3).

\section{Results}

We recorded 4,707 bee individuals representing 109 species in 21 genera and six families (Online Resource 1). The most abundant and most frequent species were Bombus lapidarius (19.2\%), Apis mellifera (16.3\%), Bombus pascuorum (9.7\%), Bombus terrestris (6.3\%), Halictus tumulorum (5.7\%), Lasioglossum pauxillum (5.4\%), and Osmia bicolor (4.3\%). Honey bees were not included in any of the analyses because occurrence and densities of A. mellifera are largely determined by beekeepers.

Species richness of bees

A hierarchical partitioning model (Table 1) revealed that habitat area was the key factor in determining species richness of bees. Species numbers increased significantly with increasing size of grassland fragments (Table 1, Fig. 1a). Habitat area was also the most important factor in determining estimated species richness and species richness based on equal sample size showing also a significant positive slope (estimated: $F_{1,30}=24.43, r=0.67, p<0.001 ; y=$ $17.52 x-17.72$; equal sample size: $F_{1,30}=8.44$, $r=0.47, p=0.007 ; y=3.61 x+6.79)$.

When we analyzed the effects of surrounding landscape diversity on bee species richness at twelve different spatial scales (ranging from 250 to 3,000 m radius around the calcareous grasslands), we found the most significant correlations at the smallest scale of radius $250 \mathrm{~m}$ (Fig. 2). The 500 and $750 \mathrm{~m}$ scales were still marginally significant. Therefore, in all multifactorial analyses, landscape diversity at a radius of $250 \mathrm{~m}$ was used. The hierarchical partitioning model showed landscape diversity as the second most important factor, positively influencing bee species richness after habitat area (Table 1, Fig. 1b). When plotting standardized residuals versus leverage no data points exceeded the critical Cook's distance values for extreme influence on the regression line, excluding the possibility of results being skewed by outliers. Removing any of the three data points representing low landscape diversity did not affect the significant relationship in two cases and resulted in a marginally significant relationship in one case $\left(F_{1,29}=5.04\right.$, $p=0.033, F_{1,29}=6.22, p=0.019, F_{1,29}=4.08$, $p=0.053$, respectively).

Life history traits of bees

Hierarchical partitioning models illustrated that mean ITD as a measure of dispersal ability was affected by habitat area as well as landscape diversity (Table 2). Average body size of all species decreased with increasing habitat area (Fig. 3a) and increasing landscape diversity (Fig. 3b), i.e. small bee species were more often observed in large fragments and in fragments surrounded by a diverse landscape. Similarly to bee species richness, critical Cook's distance values were not exceeded by any data points and removing any of the three data points representing low landscape diversity did not affect the significant relationship $\left(F_{1,29}=5.38, p=0.028, F_{1,29}=6.05\right.$, $p=0.021, F_{1,29}=6.06, p=0.032$, respectively).

We compared 28 species of cleptoparasitic bees to 80 species of nest-building bees. Because the results for the entire bee community might be biased due to correlations between traits, we tested trait-related responses in a second step within the family Halictidae only. Nine species of cuckoo bees (genus Sphecodes) were compared to 19 potential host species (genera Halictus and Lasioglossum). There were significant interactions between trophic level and habitat area in their effect on species richness, concerning all bees as well as halictids only (Table 3 ). In contrast to expectations, nest-builders showed sharper declines than the higher trophic level cleptoparasites (Fig. 4a, b). These patterns were similar for the analysis of the entire bee community as well as for halictid bees alone.

We further compared 16 species of social bees and 61 species of solitary bees. Here, we also analyzed social versus solitary bees within the family of Halictidae separately; eight social bee species and eight solitary species (the social status of three species is unclear).

There were significant interactions between sociality and habitat area in their effect on species richness (Table 3). Looking at the entire community, species 
Table 1 Relative importance of the five explanatory variables for bee species richness (contribution of each variable within independent and joint contributions separately from hierarchical partitioning models)

\begin{tabular}{|c|c|c|c|c|}
\hline & Variable in model & $\begin{array}{l}\text { Independent } \\
\text { contribution }(\%)\end{array}$ & $\begin{array}{l}\text { Joint } \\
\text { contr. }(\%)\end{array}$ & $\begin{array}{l}\text { Full model } \\
\text { multiple } r^{2}\end{array}$ \\
\hline \multirow[t]{6}{*}{ Observed species richness } & & & & 0.707 \\
\hline & Habitat area & 68.7 & 37.6 & \\
\hline & Habitat connectivity & 4.4 & 0.7 & \\
\hline & Landscape diversity & 14.4 & 29.1 & \\
\hline & Flower cover & 6.0 & 22.2 & \\
\hline & Flower spec. richness & 6.6 & 10.4 & \\
\hline \multirow[t]{6}{*}{ Estimated species richness } & & & & 0.621 \\
\hline & Habitat area & 57.8 & 36.5 & \\
\hline & Habitat connectivity & 12.7 & 1.2 & \\
\hline & Landscape diversity & 18.4 & 30.9 & \\
\hline & Flower cover & 5.2 & 23.3 & \\
\hline & Flower spec. richness & 6.0 & 10.1 & \\
\hline \multirow[t]{6}{*}{ Equal sample size species richness (20 min) } & & & & 0.436 \\
\hline & Habitat area & 40.7 & 25.3 & \\
\hline & Habitat connectivity & 13.6 & 0.7 & \\
\hline & Landscape diversity & 29.5 & 30.0 & \\
\hline & Flower cover & 8.4 & 27.4 & \\
\hline & Flower spec. richness & 7.7 & 16.4 & \\
\hline
\end{tabular}

richness of solitary bees was more sensitive to area loss, as indicated by a steeper slope of the species-area relationship than species richness of social bees (Fig. 4c). When we tested trait-related responses within the family Halictidae only, we observed a different pattern. Comparing social and solitary halictid bees, species richness of social halictid bees decreased more strongly with decreasing habitat area than species richness of solitary halictid bees (Fig. 4d).

Additional analyses of species-area relationships at the $\log -\log$ scale were performed to compare the proportional loss of species between trait groups with different absolute species richness (Online Resource 4). The results show no significant slope differences for nest-building versus cleptoparasitic bee species. The comparison of slopes for all solitary versus social species was significant whereas within the halictids slope differences were not significant (Online Resource 4).

Interactions between sociality or trophic level and connectivity, flower cover, and flower species richness, respectively, did not have significant effects on species richness of bees (Online Resource 5).

\section{Discussion}

Habitat area and, to a lesser degree, the diversity of the surrounding landscape were the most important factors explaining species richness patterns of wild bees in fragmented calcareous grasslands, indicating that habitat loss and landscape homogenization are essential drivers of pollinator loss. The strength of these adverse effects was dependent on the life history traits of bees such as dispersal ability (measured as ITD), sociality, and trophic level. Hence, land-use change can be considered a major driver for shifts in species composition in fragmented habitats (McKinney and Lockwood 1999).

A reduction in habitat area is generally expected to have a strong, negative impact on biodiversity (Fahrig 2003). In our study, we show that decreasing fragment area reduced bee species richness. These results confirm species-area relationships that were demonstrated in other studies of bees in subtropical dry forests (Aizen and Feinsinger 1994), limestone quarries (Krauss et al. 2009), orchard meadows (SteffanDewenter 2003), and desert scrub (Cane et al. 2006). Possible explanations include higher local extinction 


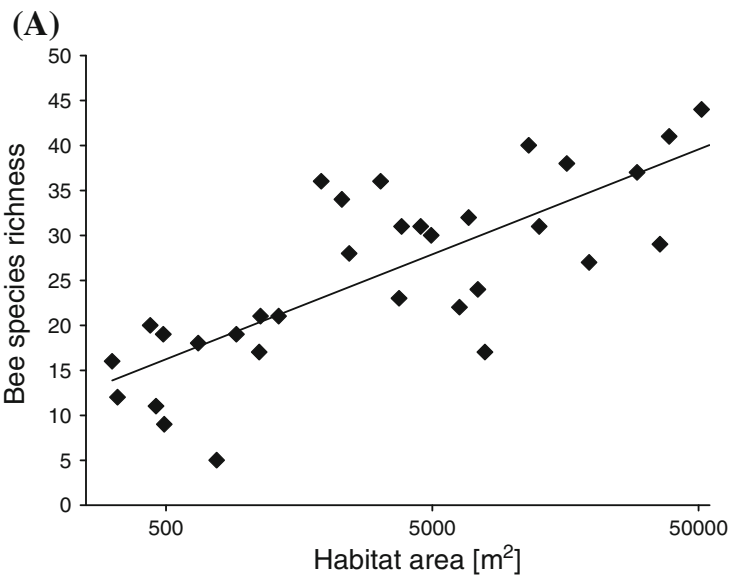

(B)

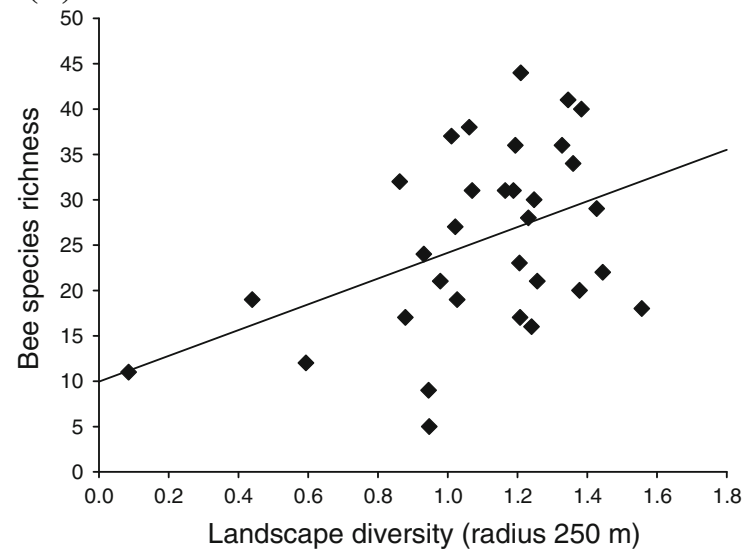

Fig. 1 Relationship between bee species richness and a habitat area (simple regression: $F_{1,30}=43.98, r=0.771, p<0.0001$; $y=11.67 x-15.25)$ and $\mathbf{b}$ landscape diversity at a radius of $250 \mathrm{~m}$ (simple regression: $F_{1,30}=6.83, r=0.431, p=0.014$; $y=14.20 x+9.96)$

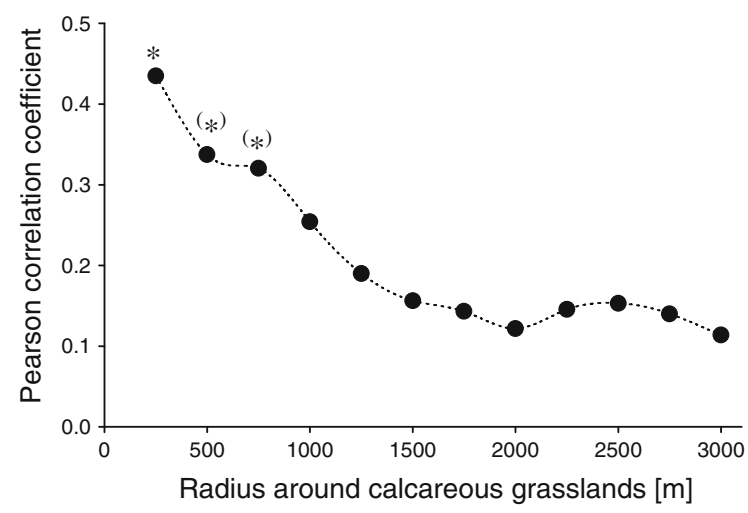

Fig. 2 Pearson correlation coefficients for bee species richness and landscape diversity (Shannon index) on 12 different scales ranging from 250 to $3,000 \mathrm{~m}$ radius. Significance levels: $* p<0.05 ;(*) p<0.1$
Table 2 Relative importance of the five explanatory variables (contribution of each variable within independent and joint contributions separately from hierarchical partitioning models) for mean body size of bee species per site (measured as intertegular distance, ITD)

\begin{tabular}{lccl}
\hline $\begin{array}{l}\text { Variable } \\
\text { in model }\end{array}$ & $\begin{array}{l}\text { Independent } \\
\text { contribution } \\
(\%)\end{array}$ & $\begin{array}{l}\text { Joint } \\
\text { contr. } \\
(\%)\end{array}$ & $\begin{array}{l}\text { Full model } \\
\text { Multiple } r^{2}\end{array}$ \\
\hline Mean body size (ITD) & & & 0.503 \\
Habitat area & 53.0 & 36.6 & \\
Habitat connectivity & 8.5 & 2.1 & \\
Landscape diversity & 24.9 & 25.0 & \\
Flower cover & 6.9 & 17.6 & \\
Flower spec. richness & 7.1 & 18.7 & \\
\hline
\end{tabular}

rates due to thresholds of minimum viable populations, the lack of key resources in small habitat fragments, or variations in recolonization rates.

The ability to move between habitat fragments depends on the dispersal capacity of a species (Hanski and Ovaskainen 2000). Body size of bees, here measured as ITD, is closely related to foraging distances (Gathmann and Tscharntke 2002; Greenleaf et al. 2007). In our study ITD decreased with increasing habitat area, i.e. a higher proportion of large bee species occurred in small habitat fragments. We conclude that large bee species with greater mobility are less prone to the effects of habitat loss. We attribute this to their larger foraging ranges allowing the use of food resources in spatially isolated habitat patches and increasing recolonization capacity. In contrast, small bees have small foraging ranges and therefore require a higher density of available food and nesting resources per unit area (Cresswell et al. 2000). The large calcareous grasslands among our study sites offered a higher density and richness of flowering plant species and may further supply more diverse nesting resources. They may thus provide foraging as well as nesting sites in one place and therefore be more suitable for small bees with limited foraging ranges.

The few studies comparing responses of pollinating insects differing in body size to area loss have given ambiguous results (Steffan-Dewenter and Tscharntke 2000; Shahabuddin and Ponte 2005; Cane et al. 2006). A recent meta-analysis examining five field studies, including data from this study, found a general trend across northern Europe for a higher sensitivity of small polylectic and solitary bees to habitat loss compared to 

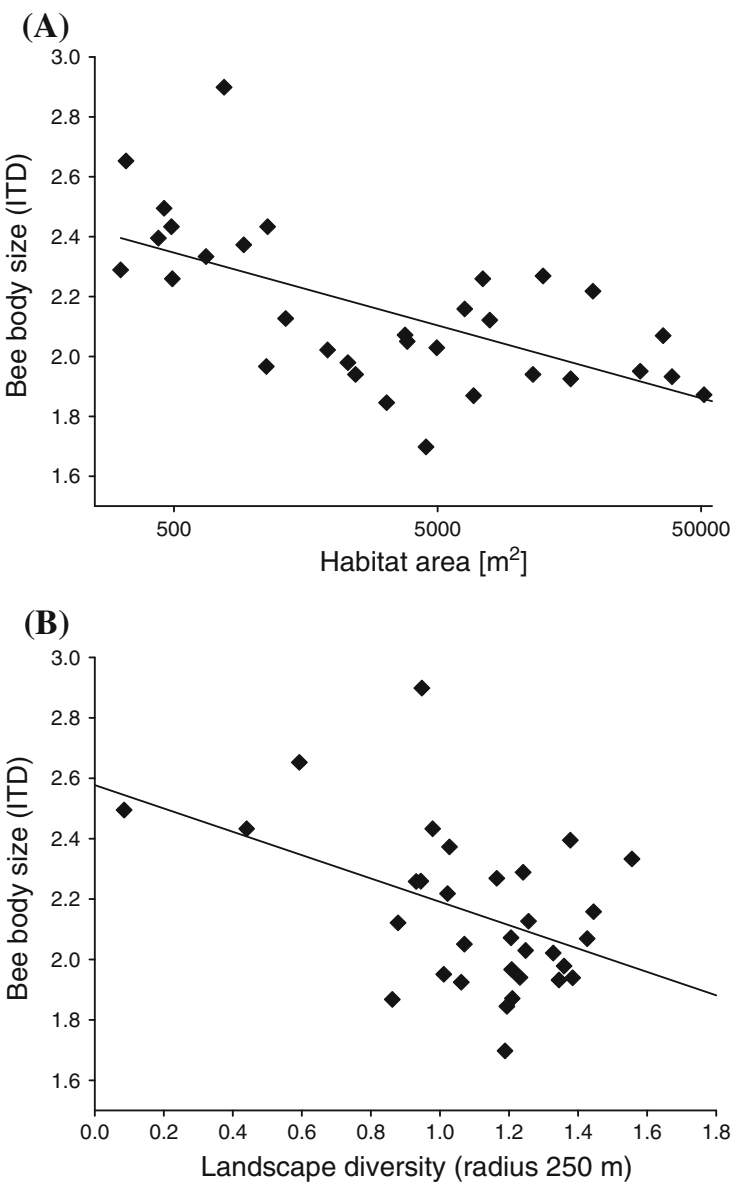

Fig. 3 Relationship between average body size of all occurring bee species (measured as inter-tegular distance, ITD) and a habitat area (simple regression: $F_{1,30}=18.49, r=0.617$, $p<0.001 ; y=-0.24 x+3.00)$ and $\mathbf{b}$ landscape diversity (simple regression: $F_{1,30}=7.66, \quad r=0.451, \quad p=0.010$; $y=-0.39 x+2.58)$

large polylectic and social bees (Bommarco et al. 2010). However, generalizations have to be handled with care as other life history traits may be correlated with body size, impeding conclusions about the dependency of local extinction risk on specific life history traits.

For example, it could be assumed that social bees, due to their greater efficiency in utilizing resources, can buffer the effects of habitat loss. When comparing the responses of social and solitary halictids to reduced habitat area, however, species richness of social halictids was more sensitive to area loss than species richness of solitary halictids. Our results of the halictids seem to be in contrast to other studies comparing species-area relationships between social and solitary bees. Krauss et al. (2009) found a significantly stronger effect of habitat loss on solitary bees whereas Bommarco et al. (2010) found no distinction between bee groups with differing social behavior. These studies, however, included bumblebees in the social group, thereby mixing two traits, namely sociality and body size. When we did the trait analysis with all sampled solitary and social bees (including bumblebees in the latter group), we too found that social bee richness was less prone to the effects of habitat loss than solitary bee richness. Bumblebees are particularly large bees with large foraging ranges and benefit from mass flowering crops and semi-natural habitats scattered in the landscape matrix surrounding their colonies (Westphal et al. 2003; Diekötter et al. 2010), thereby presumably reducing the sensitivity to local habitat loss. In contrast, social and solitary species within the halictids are similar in body size (mean $\operatorname{ITD}_{\text {social }}=1.43 \pm$ $0.29 \mathrm{~mm}$, mean $\mathrm{ITD}_{\text {solitary }}=1.41 \pm 0.30 \mathrm{~mm}$ ). In our analysis, they should therefore not differ significantly in their dispersal ability or foraging range. The observed higher sensitivity of social bees may instead be due to their need of providing food to a large number of larvae within the colony. Social halictid bees may therefore rely on larger calcareous grasslands that offer a higher density of resources within a limited foraging radius.

The analysis at the $\log -\log$ scale showed no contrasting patterns in relative changes, i.e. the proportional loss of social and solitary halictid species was similar, although a greater loss in absolute species numbers occurred within the social halictids. Taking into account that the total number of species in each trait group was the same (eight social bee species versus eight solitary species), we can exclude a possible bias due to different absolute richness. When considering the entire community, in contrast, solitary bees responded more sensitive to habitat loss both in relative and in absolute species numbers.

Resource diversity does not seem to play a role in determining differences of social versus solitary halictid bees. We are able to rule out the possible interference of the traits sociality and diet breadth (Davies et al. 2004) because all of the halictid species sampled in this study are considered to be polylectic, i.e. generalist species with regard to their pollen source (Westrich 1989). However, among the other sampled solitary bees, there are 18 oligolectic species whereas 
Table 3 Mixed effects models for the two explanatory variables habitat area and landscape diversity (radius $250 \mathrm{~m}$ ), the trait categories trophic level (cleptoparasitic versus nestbuilding) and sociality (solitary versus social) of all bee species and halictid bee species only and the interaction of explanatory variables and trait categories in 32 calcareous grasslands. For results of all factors see Online Resource 5

\begin{tabular}{|c|c|c|c|c|c|c|}
\hline & & \multirow[t]{2}{*}{ d.f. } & \multicolumn{2}{|c|}{$\begin{array}{l}\text { All bees species } \\
\text { richness }\end{array}$} & \multicolumn{2}{|c|}{$\begin{array}{l}\text { Halictidae } \\
\text { species richness }\end{array}$} \\
\hline & & & $F$ & $p$ & $F$ & $p$ \\
\hline \multirow[t]{6}{*}{ Trophic level: nest-building versus cleptoparasitic } & Trophic level & 1,30 & 240.23 & $<0.001$ & 157.03 & $<0.001$ \\
\hline & Habitat area & 1,30 & 43.98 & $<0.001$ & 31.30 & $<0.001$ \\
\hline & Trophic level $\times$ habitat area & 1,30 & 23.71 & $<0.001$ & 15.80 & $<0.001$ \\
\hline & Trophic level & 1,30 & 139.48 & $<0.001$ & 106.01 & $<0.001$ \\
\hline & Landscape diversity & 1,30 & 6.83 & 0.014 & 5.49 & 0.026 \\
\hline & Trophic level $\times$ landsc. diversity & 1,30 & 1.19 & 0.284 & 0.92 & 0.346 \\
\hline \multirow[t]{6}{*}{ Sociality: social versus solitary } & Sociality & 1,30 & 56.85 & $<0.001$ & 78.69 & $<0.001$ \\
\hline & Habitat area & 1,30 & 44.12 & $<0.001$ & 44.40 & $<0.001$ \\
\hline & Sociality $\times$ habitat area & 1,30 & 20.90 & $<0.001$ & 7.91 & 0.009 \\
\hline & Sociality & 1,30 & 36.55 & $<0.001$ & 63.27 & $<0.001$ \\
\hline & Landscape diversity & 1,30 & 4.61 & 0.040 & 5.35 & 0.028 \\
\hline & Sociality $\times$ landsc. diversity & 1,30 & 2.72 & 0.109 & 0.48 & 0.491 \\
\hline
\end{tabular}

(A)

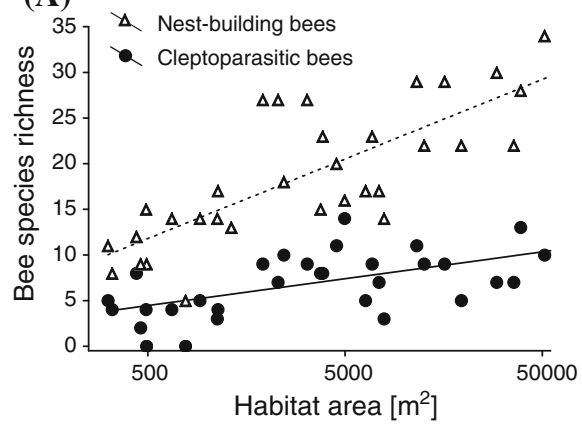

(C)

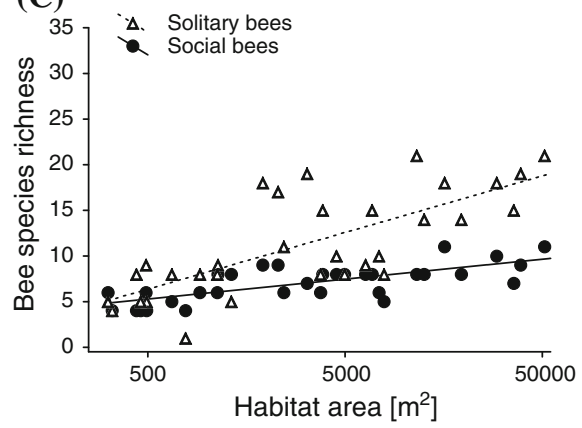

Fig. 4 Trait analysis of all bees and members of the family Halictidae only. Relationship between species richness of nestbuilding and cleptoparasitic bees for $\mathbf{a}$ all bees (nest-building bee species $n=80: y=8.72 x-11.76$, cleptoparasitic species $n=28: \quad y=2.94 x-3.49$ ) and b Halictidae (nest-building species $n=19: \quad y=3.34 x-6.43$; cleptoparasitic species
(B)

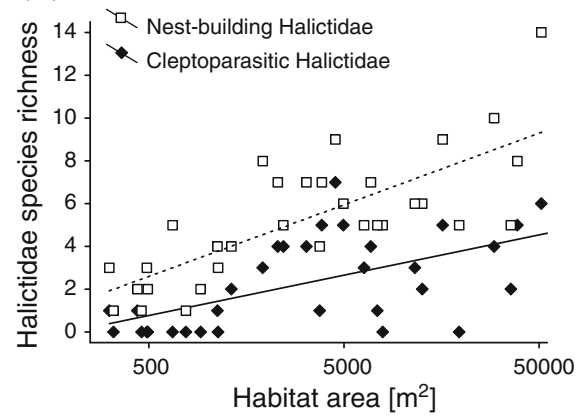

(D)

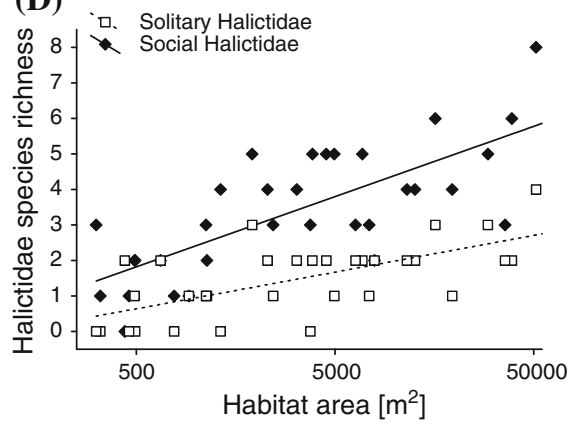

$n=9: y=1.88 x-4.32$ ). Relationship between species richness of solitary and social bees for $\mathbf{c}$ all bees (solitary species $n=61: \quad y=6.20 x-10.37$, social species $n=16: \quad y=$ $2.18 x-0.61$ ) and $\mathbf{d}$ Halictidae (solitary species $n=8: y=$ $1.04 x-2.15$, social species $n=8: y=1.98 x-3.52$ ) 
social bees are entirely polylectic. Oligolectic species, i.e. specialists are assumed to have higher extinction risks because their key resources may be missing in the remaining habitat fragments (Henle et al. 2004). These specialist bees may constitute another explanation for the observed stronger effect of habitat loss on solitary bee species richness versus social bee species richness when including all six sampled bee families in the analysis.

Species at higher trophic levels with a narrow host range are generally thought to be more affected by habitat loss because they depend on the occurrence of their host species at lower trophic levels (Holt et al. 1999; Ewers and Didham 2006). Cleptoparasitic bees depend on the occurrence of nest-building species as they feed on the host's brood cell provisions. However, contrary to our predictions, cleptoparasitic halictids were not more prone to habitat loss. Rather, nestbuilding species, contributing generally more species in large fragments, seem to suffer more from a reduction in habitat area. A similar effect could be observed for bees in limestone quarries (Krauss et al. 2009). As cleptoparasites do not commute between foraging places and a nest, they may utilize their energy for dispersal and host detection instead. A higher mobility of cleptoparasites and lower host specificity of remaining cleptoparasitic species might explain the unexpected lower sensitivity of the higher trophic level to habitat loss. Because the list of potential hosts is not complete for many cleptoparasites, a direct comparison between parasites and their hosts is not possible yet. It remains to be determined if the observed pattern results in increasing top-down effects of more generalized cleptoparasites on host species potentially amplifying species loss in small habitat fragments.

Few empirical fragmentation studies include matrix quality at different spatial scales in addition to habitat area and connectivity in their analyses (Krauss et al. 2003; Öckinger and Smith 2006; Meyer et al. 2009). In addition to habitat area, landscape diversity also influenced the distribution of wild bee species in our study, even though explaining less variance than habitat area. A high heterogeneity of the surrounding landscape constituting other extensive grasslands, fallows, orchard meadows, hedgerows and gardens presumably provides additional foraging plants and a variety of nesting resources and is beneficial for wild bees (Steffan-Dewenter 2003; Holzschuh et al. 2008). The utilization of partial habitats by bees in diverse landscapes may benefit from matrix permeability, facilitating colonization and reducing extinction rates in habitat fragments (Ricketts 2001; Fahrig et al. 2011). It is further possible that bees in grassland fragments surrounded by a homogeneous agricultural landscape may suffer from negative edge effects such as insecticide drift from neighboring crop fields.

The landscape directly adjacent to the calcareous grasslands was most relevant to bees, as landscape diversity within a $250 \mathrm{~m}$ radius around the center of the calcareous grasslands was the best scale predicting bee species richness. This corresponds to foraging ranges of solitary wild bees that are between 150 and $400 \mathrm{~m}$ (Gathmann and Tscharntke 2002). Larger bees with larger foraging ranges (Westphal et al. 2006) are able to benefit from partial habitats at greater distances from the calcareous grasslands. Accordingly, we were able to show that larger bees persist in homogeneous landscapes whereas smaller bee species were more often only observed in fragments surrounded by a diverse landscape.

The utilization of partial habitats in the landscape, in combination with the low degree of isolation of the grassland fragments (between 55 and 1,894 m distance to their nearest neighbor), might be the reason for the lack of positive effects of connectivity on wild bee communities. This result is in accordance with 54 of 81 reviewed studies (Watling and Donnelly 2006) that showed no relationship between animal species richness and isolation. However, in a recent trait analysis by Williams et al. (2010), isolation had a stronger effect on social versus solitary and on small versus large bees, although these differential effects disappeared when honey bees were removed from the analysis. Nevertheless, present-day species distributions may be a result of historical habitat connectivity that has by now been lost due to habitat destruction and land-use intensification and many local extinction events may not yet have occurred (Kuussaari et al. 2009; Krauss et al. 2010).

The empirical evidence presented here suggests that pollinator species richness is profoundly dependent on the size of semi-natural habitats such as calcareous grasslands. Therefore, nature conservation agencies and agri-environment schemes need to continue and expand support for extensive management in this protected biotope by sheep herders, land managers and environmental organizations, whose work prevents succession in calcareous grasslands to 
scrubland and forest. We also showed that wild bees benefit from a complex landscape around semi-natural grasslands. Therefore, in addition to the protection of single habitat fragments, management schemes for conservation of bees as key pollinators should also aim to preserve heterogeneity of surrounding landscapes, thereby providing a greater array of food and nesting resources and offering corridors to reduce patch isolation. Organic agriculture for example increases floral diversity and abundance, especially in structurally simple landscapes, and leads to higher bee diversity (Holzschuh et al. 2007). Yet, further research on the relative importance of different scheme types is needed. While small species seem to be generally more sensitive to changes in habitat area and landscape diversity, distinct functional groups defined by additional traits within size classes might be further jeopardized because their responses to landscape change can be blurred by general trends of the whole bee community.

Acknowledgments We thank the owners and sheep herders of the calcareous grasslands for their cooperation during the field season, Reiner Theunert for help in determination of difficult bee species, and Jim des Lauriers, Oliver Schweiger and anonymous reviewers for helpful comments on the manuscript. This work has been funded by the European Union FP 6 Integrated project ALARM (Assessing Large scale environmental Risks for biodiversity with tested Methods), Pollinator Module (GOCECT-2003-506675) and in part by the FP 7 EU-project SCALES ("Securing the Conservation of biodiversity across Administrative Levels and spatial, temporal and Ecological Scales"; project \#226852)

\section{References}

Aizen MA, Feinsinger P (1994) Habitat fragmentation, native insect pollinators, and feral honey-bees in Argentine Chaco Serrrano. Ecol Appl 4:378-392

Aizen MA, Garibaldi LA, Cunningham SA, Klein AM (2009) How much does agriculture depend on pollinators? Lessons from long-term trends in crop production. Ann Bot 103:1579-1588

Bielby J, Cardillo M, Cooper N, Purvis A (2010) Modelling extinction risk in multispecies data sets: phylogenetically independent contrasts versus decision trees. Biodivers Conserv 19:113-127

Biesmeijer JC, Roberts SPM, Reemer M, Ohlemüller R, Edwards M, Peeters T, Schaffers AP, Potts SG, Kleukers R, Thomas CD, Settele J, Kunin WE (2006) Parallel declines in pollinators and insect-pollinated plants in Britain and the Netherlands. Science 313:351-354
Blüthgen N, Klein A-M (2011) Functional complementarity and specialisation: the role of biodiversity in plant-pollinator interaction. Basic Appl Ecol 12:282-291

Bommarco R, Biesmeijer JC, Meyer B, Potts SG, Pöyry J, Roberts SP, Steffan-Dewenter I, Ockinger E (2010) Dispersal capacity and diet breadth modify the response of wild bees to habitat loss. P Roy Soc Lond B-Biol Sci 277:2075-2082

Brückmann S, Krauss J, Steffan-Dewenter I (2010) Butterfly and plant specialists suffer from reduced connectivity in fragmented landscapes. J Appl Ecol 47:799-809

Burd M (1994) Bateman principle and plant reproduction-the role of pollen limitation in fruit and seed set. Bot Rev 60:83-139

Cane JH (1987) Estimation of bee size using intertegular span (Apoidea). J Kansas Entomol Soc 60:145-147

Cane JH, Minckley RL, Kervin LJ, Roulston TH, Williams NM (2006) Complex responses within a desert bee guild (Hymenoptera: Apiformes) to urban habitat fragmentation. Ecol Appl 16:632-644

Chevan A, Sutherland M (1991) Hierarchical partitioning. Am Stat 45:90-96

Colwell RK (2004) EstimateS, Version 7: Statistical estimation of species richness and shared species from samples (software and user's guide). Available from http://viceroy. eeb.uconn.edu/EstimateS. Accessed 14 Mar 2006

Cresswell JE, Osborne JL, Goulson D (2000) An economic model of the limits to foraging range in central place foragers with numerical solutions for bumblebees. Ecol Entomol 25:249-255

Danforth BN (2002) Evolution of sociality in a primitively eusocial lineage of bees. Proc Natl Acad Sci USA 99: 286-290

Danforth BN, Eardley C, Packer L, Walker K, Pauly A, Randrianambinintsoa FJ (2008) Phylogenie of Halictidae with an emphasis on endemic African Halictinae. Apidologie 39:86-101

Davies KF, Margules CR, Lawrence JF (2004) A synergistic effect puts rare, specialized species at greater risk of extinction. Ecology 85:265-271

Diekötter T, Kadoya T, Peter F, Wolters V, Jauker F (2010) Oilseed rape crops distort plant-pollinator interactions. J Appl Ecol 47:209-214

Ewers RM, Didham RK (2006) Confounding factors in the detection of species responses to habitat fragmentation. Biol Rev Camb Philos Soc 81:117-142

Fahrig L (2003) Effects of habitat fragmentation on biodiversity. Annu Rev Ecol Evol Syst 34:487-515

Fahrig L, Baudry J, Brotons L, Burel FG, Crist TO, Fuller RJ, Sirami C, Siriwardena GM, Martin JL (2011) Functional landscape heterogeneity and animal biodiversity in agricultural landscapes. Ecol Lett 14:101-112

Franzén M, Schweiger O, Betzholtz P-E (2012) Species-area relationships are controlled by species traits. PLoS ONE 7:e37359

Gathmann A, Tscharntke T (2002) Foraging ranges of solitary bees. J Anim Ecol 71:757-764

Greenleaf SS, Williams NM, Winfree R, Kremen C (2007) Bee foraging ranges and their relationship to body size. Oecologia 153:589-596 
Hanski I (1999) Metapopulation Ecology. Oxford University Press, New York

Hanski I, Ovaskainen O (2000) The metapopulation capacity of a fragmented landscape. Nature 404:755-758

Hanski I, Alho J, Moilanen A (2000) Estimating the parameters of survival and migration of individuals in metapopulations. Ecology 81:239-251

Hendrickx F, Maelfait JP, Desender K, Aviron S, Bailey D, Diekotter T, Lens L, Liira J, Schweiger O, Speelmans M, Vandomme V, Bugter R (2009) Pervasive effects of dispersal limitation on within- and among-community species richness in agricultural landscapes. Glob Ecol Biogeogr 18:607-616

Henle K, Davies KF, Kleyer M, Margules C, Settele J (2004) Predictors of species sensitivity to fragmentation. Biodivers Conserv 13:207-251

Holt RD, Lawton JH, Polis GA, Martinez ND (1999) Trophic rank and the species-area relationship. Ecology 80:1495-1504

Holzschuh A, Steffan-Dewenter I, Kleijn D, Tscharntke T (2007) Diversity of flower-visiting bees in cereal fields: effects of farming system, landscape composition and regional context. J Appl Ecol 44:41-49

Holzschuh A, Steffan-Dewenter I, Tscharntke T (2008) Agricultural landscapes with organic crops support higher pollinator diversity. Oikos 117:354-361

Jauker F, Diekötter T, Schwarzbach F, Wolters V (2009) Pollinator dispersal in an agricultural matrix: opposing responses of wild bees and hoverflies to landscape structure and distance from main habitat. Landscape Ecol 24:547-555

Kearns CA, Inouye DW, Waser NM (1998) Endangered mutualisms: the conservation of plant-pollinator interactions. Annu Rev Ecol Syst 29:83-112

Klein AM, Vaissière BE, Cane JH, Steffan-Dewenter I, Cunningham SA, Kremen C, Tscharntke T (2007) Importance of pollinators in changing landscapes for world crops. P Roy Soc Lond B Biol Sci 274:303-313

Krauss J, Steffan-Dewenter I, Tscharntke T (2003) How does landscape context contribute to effects of habitat fragmentation on diversity and population density of butterflies? J Biogeogr 30:889-900

Krauss J, Alfert T, Steffan-Dewenter I (2009) Habitat area but not habitat age determines wild bee richness in limestone quarries. J Appl Ecol 46:194-202

Krauss J, Bommarco R, Guardiola M, Heikkinen RK, Helm A, Kuussaari M, Lindborg R, Ockinger E, Pärtel M, Pino J, Pöyry J, Raatikainen KM, Sang A, Stefanescu C, Teder T, Zobel M, Steffan-Dewenter I (2010) Habitat fragmentation causes immediate and time-delayed biodiversity loss at different trophic levels. Ecol Lett 13:597-605

Kuussaari M, Bommarco R, Heikkinen RK, Helm A, Krauss J, Lindborg R, Ockinger E, Pärtel M, Pino J, Rodà F, Stefanescu C, Teder T, Zobel M, Steffan-Dewenter I (2009) Extinction debt: a challenge for biodiversity conservation. Trends Ecol Evol 24:564-571

LaSalle J, Gauld ID (1993) Hymenoptera: their diversity, and their impact on the diversity of other organisms. In: LaSalle J, Gauld ID (eds) Hymenoptera and biodiversity. CAB International, Wallingford, pp 1-26

Mac Nally R, Walsh CJ (2004) Hierarchical partitioning publicdomain software. Biodiv Conserv 13:659-660
Matthies D, Bräuer I, Maibon W, Tscharntke T (2004) Population size and the risk of local extinction: empirical evidence from rare plants. Oikos 105:481-488

McKinney ML, Lockwood JL (1999) Biotic homogenization: a few winners replacing many losers in the next mass extinction. Trends Ecol Evol 14:450-453

Meyer B, Jauker F, Steffan-Dewenter I (2009) Contrasting resource-dependent responses of hoverfly richness and density to landscape structure. Basic Appl Ecol 10:178-186

Moore RP, Robinson WD, Lovette IJ, Robinson TR (2008) Experimental evidence for extreme dispersal limitation in tropical forest birds. Ecol Lett 11:960-968

Öckinger E, Smith HG (2006) Landscape composition and habitat area affects butterfly species richness in semi-natural grasslands. Oecologia 149:526-534

Olea PP, Mateo-Tomás P, de Frutos Á (2010) Estimating and modelling bias of the hierarchical partitioning publicdomain software: implications in environmental management and conservation. PLoS ONE 5(7):e11698. doi: 10.1371/journal.pone.0011698

Palmer MW (1991) Estimating species richness: the secondorder jackknife reconsidered. Ecology 72:1512-1513

Pinheiro J, Bates D, DebRoy S, Sarkar D, R Development Core Team. (2009). NLME: linear and nonlinear mixed effects models. $\mathrm{R}$ package version 3.1-93

Poschlod P, WallisDeVries MF (2002) The historical and socioeconomic perspective of calcareous grasslands-lessons from the distant and recent past. Biol Conserv 104:361-376

Rathcke BJ, Jules ES (1993) Habitat fragmentation and plantpollinator interactions. Curr Sci India 65:273-277

Ricketts TH (2001) The matrix matters: effective isolation in fragmented landscapes. Am Nat 158:87-99

Ricklefs RE, Lovette IJ (1999) The roles of island area per se and habitat diversity in the species-area relationships of four Lesser Antillean faunal groups. J Anim Ecol 68: $1142-1160$

Rosenzweig ML (1995) Species diversity in space and time. Cambridge University Press, Cambridge

Shahabuddin G, Ponte CA (2005) Frugivorous butterfly species in tropical forest fragments: correlates of vulnerability to extinction. Biodivers Conserv 14:1137-1152

Smith EP, van Belle G (1984) Nonparametric estimation of species richness. Biometrics 40:119-129

Steffan-Dewenter I (2003) Importance of habitat area and landscape context for species richness of bees and wasps in fragmented orchard meadows. Conserv Biol 17:1036-1044

Steffan-Dewenter I, Tscharntke T (2000) Butterfly community structure in fragmented habitats. Ecol Lett 3:449-456

WallisDeVries MF, Poschlod P, Willems JH (2002) Challenges for the conservation of calcareous grasslands in northwestern Europe: integrating the requirements of flora and fauna. Biol Conserv 104:265-273

Watling JI, Donnelly MA (2006) Fragments as islands: a synthesis of faunal responses to habitat patchiness. Conserv Biol 20:1016-1025

Westphal C, Steffan-Dewenter I, Tscharntke T (2003) Mass flowering crops enhance pollinator densities at a landscape scale. Ecol Lett 6:961-965

Westphal C, Steffan-Dewenter I, Tscharntke T (2006) Bumblebees experience landscapes at different spatial scales: 
possible implications for coexistence. Oecologia 149: 289-300

Westphal C, Bommarco R, Carré EL, Morison N, Petanidou T, Potts SG, Stuart PM, Roberts HS, Tscheulin T, Vaissière BE, Woyciechowski M, Biesmeijer JC, Kunin WE, Settele J, Steffan-Dewenter I (2008) Measuring bee diversity in different European habitats and biogeographical regions. Ecol Monogr 78:653-671

Westrich P (1989) Die Wildbienen Baden-Württembergs. Eugen Ulmer, Stuttgart

Westrich P (1996) Habitat requirements of central European bees and the problems of partial habitats. In: Matheson A, Buchmann SL, O'Toole C, Westrich P, Williams IH (eds)
The conservation of bees. Academic Press, London, pp 1-16

Williams NM, Crone EE, Roulston TH, Minckley RL, Packer L, Potts SG (2010) Ecological and life-history traits predict bee species responses to environmental disturbances. Biol Conserv 143:2280-2291

Winfree R, Griswold T, Kremen C (2007) Effect of human disturbance on bee communities in a forested ecosystem. Conserv Biol 21:213-222

Winfree R, Aguilar R, Vázquez DP, LeBuhn G, Aizen MA (2009) A meta-analysis of bees' responses to anthropogenic disturbance. Ecology 90:2068-2076 